www.jmscr.igmpublication.org

Impact Factor 3.79

ISSN (e)-2347-176x ISSN (p) 2455-0450

crossref DOI: http://dx.doi.org/10.18535/jmscr/v3i10.61

Journal Of Medical Science And Clinical Research

\title{
Haematological Parameters in Neonatal Sepsis
}

\author{
Authors

\section{Dr Abhilasha Garg ${ }^{1}$, Dr Chandan Kr. Agrawal ${ }^{2}$, Dr Narendra Mogra} \\ Dr Pooja Kanwat ${ }^{4}$, Dr Abha Patni ${ }^{5}$ \\ ${ }^{1}$ M.D, Pathology, Assistant Professor RNT M.C. Udaipur \\ ${ }^{2}$ M.D, Assistant Professor, Ananta Medical College Udaipur \\ ${ }^{3}$ M.D, Pathology Professor and Head Geetanjali Medical College Udaipur
}

${ }^{4}$ M.D, Pathology Senior Resident RNT M.C. Udaipur, ${ }^{5}$ M.D, Pathology Professor RNT M.C. Udaipur

Corresponding Author

Dr Abhilasha Garg

M.D, Pathology, Assistant Professor RNT M.C. Udaipur

Email:drabhi14@gmail.com

\begin{abstract}
Background: In neonatal sepsis, the haematological screening parameters and Creactive protein (CRP) have wide variations in performance.

Objective: To evaluate the performance of haematological screening parameters and CRP in blood culture positive neonatal sepsis.

Methods: This prospective study was done over a period of one year. Blood samples from 100 clinically suspected neonatal septicemia cases were subjected to aerobic culture and Sepsis screen tests like CReactive protein, micro-ESR, total WBC count, Absolute neutrophil count, Immature/Total neutrophil count (I/T) ratio, Immature/mature neutrophil count $(I / T)$ ratio and platelet count. The culture results were correlated with the Sepsis screen tests.

Results: Of the 100 cases studied, $26 \%$ were blood culture positive. $72 \%$ were males. $56 \%$ were preterm and $40 \%$ were very low birth weight neonates. Early onset septicemia was more common, seen in $68 \%$ of cases than late onset septicemia (22.4\%) cases. E. Coli was the commonest organism isolated in $38.46 \%$ of cases followed by klebsiella pneumoniae \& staphylococcus aureus. Among the haematological parameters, the positivity was best with ANC \& I/T Ratio (84.61\%) and the least with platelet count (73.07\%). Any 2 or more parameters were positive in $96.15 \%$ of the subjects.

Conclusion: The sepsis parameters in predicting neonatal septicemia clinically needs further evaluation. Blood culture remains the gold standard for the diagnosis of neonatal septicemia. Combination of two or more sepsis screen parameters has better results in diagnosing neonatal septicemia compared to a single test while awaiting the blood culture results.
\end{abstract}

Keywords: Blood culture, Neonatal septicemia, Sepsis screen.

\section{INTRODUCTION}

Neonatal septicaemia encompasses various systemic infections of the newborn such as septicaemia, meningitis, pneumonia, arthritis, osteomyelitis \& urinary tract infections. ${ }^{1}$ The successful treatment and outcome of bacterial infections in neonates depend on the early initiation of appropriate antibiotic therapy. The 
positive blood culture report, which is a gold standard for the diagnosis of neonatal sepsis, requires 48-72 hours. It is time consuming. Therefore, haematological parameters can be evaluated for early diagnosis of neonatal sepsis. ${ }^{2}$ An ideal diagnostic test for neonatal sepsis should have maximum sensitivity and specificity. In recent years, various investigators have evaluated some highly sensitive and specific inflammatory markers (e.g. ELISA methods, haptoglobins, interleukins and counterimmuno electrophoresis, etc.) to diagnose neonatal sepsis. ${ }^{3}$ Early diagnosis of neonatal septicaemia is still a great challenge. For early diagnosis of neonatal septicaemia, a hematologic scoring system (HSS) of Rodwell ${ }^{4}$ [includes total \& differential leukocyte count, total neutrophil count, immature \& total neutrophil ratio (IT ratio), immature \& mature neutrophil ratio (IM ratio), total immature polymorphonuclear cell (PMNs) count \& platelet count] is preferable because it includes all parameters. Haematological parameters accurately predict the presence or absence of infection and are reliable. $^{5}$

\section{MATERIAL \& METHODS}

Present study was conducted on new born babies aged 0-28 days admitted in Bal Chikitsalay with signs \& symptoms of septicaemia to evaluate the usefulness of the total \& differential white blood cell count, morphology of neutrophils, IT ratio, IM ratio, band cell count, platelet count, ESR and the C-reactive protein as an early indicator of neonatal septicaemia in 100 cases. This study was undertaken because these are simple bed-side and cost effective tests which can be done even if the baby is on antibiotic therapy.

After the first clinical suspicion of infection, blood was taken for blood culture, blood cell count with differential count \& quantitative CRP \& micro ESR.

Blood cultures were done in all cases \& correlative evaluation between haematological parameters, C reactive protein \& blood culture reports was done. The haematological screening parameters included total leukocyte count (TLC), platelet count (PLT), micro- erythrocyte sedimentation rate (ESR), C-reactive protein (CRP), band to mature neutrophil ratio (B: N) and the presence of cytoplasmic vaccuolations $(\mathrm{CV})$ and/or toxic granulations (TG) in peripheral smear examinations. The semi quantitative measurement of CRP by the slide agglutination technique was done between the first 24- 36 hours of life. The blood culture samples included a single sample from a peripheral vein/artery which was taken under aseptic conditions before commencing antibiotics. Chest X-ray and other investigations were performed whenever indicated.

Sepsis screen was considered positive if more than two criteria were positive out of the following parameters:

a) Elevated $\mathrm{C}$-reactive protein [ $>16 \mathrm{mgm}$ /lit. on day 1 and 2 of life or more $>10$ $\mathrm{mgm} /$ lit. on subsequent days of life ]

b) Elevated micro ESR i.e. > [age + 3] $\mathrm{mm}$ in first hour in less than 3 days old neonate or $>15 \mathrm{~mm}$ in first hour at any age.

c) Leukopenia i.e. TLC < 5000/cu mm.

d) Neutropenia i.e. Absolute neutrophil count < 1500/cu mm. ${ }^{6}$

e) Elevated ratio of immature granulocyte [ band cells ] to the sum of all neutrophils, granulocytes [i.e. I/T ratio $>0.20$.]

f) Presence of toxic granules [eosinophilic granules in cytolplasm of neutrophil], cytoplasmic vacuolation \& Dohles bodies [aggregates of rough endoplasmic reticulum which stains light blue on Giemsa stain] on the smear are suggestive of sepsis.

g) Decreased platelet counts $<1.5 \mathrm{lacs} / \mathrm{cu}$ $\mathrm{mm}$.

h) Positive blood culture

\section{OBSERVATIONS}

Neonates who were clinically suspected to have bacterial infections within the first 48 hours of life, based on the risk factors and/or clinical features, were subjected to various haematological 
screening parameters and blood cultures. Out of 100 cases number of early onset sepsis cases were more than late onset sepsis cases \& they were 68 percent. Out of 100 cases studied, 72 were male and 28 were female with a ratio of 2.57:1.

In the present study out of 100 cases only 26 cases were culture positive, amongst which 22 cases of early onset sepsis \& only 4 cases of late onset sepsis showed culture positivity.

Leucopenia was found in more cases than leucocytosis.

Neutropenia, I/T ratio and CRP were positive in higher proportion of culture positive cases in percent of $84.61,84.61 \& 92.30$ respectively.
Neutropenia, Leucopenia/Leucocytosis, increased immature cells and Thrombocytopenia were positive in higher proportion in culture proven cases compared to culture negative cases.

Raised micro ESR \& CRP showed higher number of false positive cases in respect to culture positivity.

All screening parameters were significant with respect to culture proven sepsis. The findings of various sepsis screen parameters in relation of blood culture positive \& negative cases have been tabulated in Table 1

Table 1: Distribution Of Cases According To Sepsis Screen Perameters In The Present Study

\begin{tabular}{|c|c|c|c|c|c|c|c|}
\hline \multirow[t]{2}{*}{$\begin{array}{l}\text { S. } \\
\text { No. }\end{array}$} & \multirow[t]{2}{*}{ Parameters } & \multicolumn{2}{|c|}{ Culture positive $(n=26)$} & \multicolumn{2}{|c|}{$\begin{array}{l}\text { Culture negative } \\
\qquad(n=74)\end{array}$} & \multicolumn{2}{|c|}{ Total cases } \\
\hline & & No. & Percentage & No. & Percentage & No. & Percentage \\
\hline 1 & $\begin{array}{l}\text { Raised micro ESR (> } \\
15 \mathrm{~mm} \text { in } 1^{\text {st }} \mathrm{hr} \text { or Age } \\
+3 \text { in } 1^{\text {st }} \mathrm{hr} \text { in }<3 \text { days } \\
\text { old) }\end{array}$ & 20 & 76.92 & 50 & 67.56 & 70 & 70 \\
\hline 2 & $\begin{array}{l}\text { TLC } \\
\text { Less than } 5000 / \mathrm{cmm} \text { or } \\
25000,30000 \& 21000 \\
\text { at birth, } 12-24 \mathrm{hrs} \& \\
\text { day } 2 \text { onwards. }\end{array}$ & 21 & 80.76 & 20 & 27.02 & 41 & 41 \\
\hline 3 & $\mathrm{ANC}(<1500 / \mathrm{cmm})$ & 22 & 84.61 & 15 & 20.27 & 37 & 37 \\
\hline 4 & I/T Ratio(>0.2) & 22 & 84.61 & 10 & 13.51 & 32 & 32 \\
\hline 5 & I/M Ratio(>.3) & 21 & 80.76 & 15 & 20.27 & 37 & 37 \\
\hline 6 & $\begin{array}{l}\text { Platelet count } \quad(<1.5 \\
\text { lakh })\end{array}$ & 19 & 73.07 & 25 & 33.78 & 44 & 44 \\
\hline 7 & $\begin{array}{l}\text { PBF (toxic granules, } \\
\text { cytoplasmic } \\
\text { vacuolations \& Dohle } \\
\text { bodies) }\end{array}$ & 20 & 76.92 & 18 & 24.32 & 38 & 38 \\
\hline 8 & $\begin{array}{l}\text { CRP }\left(>16 \mathrm{mg} / \mathrm{dl} \text { on } 1^{\text {st }}\right. \\
\& 2^{\text {nd }} \text { day, }>10 \mathrm{mg} \text { on } \\
\text { subsequent days })\end{array}$ & 24 & 92.30 & 66 & 89.18 & 90 & 90 \\
\hline 9 & $>2$ parameters positive & 25 & 96.15 & 9 & 12.16 & 34 & 34 \\
\hline
\end{tabular}


In present study CRP (92.30 percent) followed by Neutropenia \& I/T ratio (84.61 percent) showed good sensitivity.

Highest specificity shown by $\mathrm{I} / \mathrm{T}$ ratio $(86.49$ percent) followed by I/M Ratio \& Neutropenia (79.72 percent).
If two or more of the above tests were positive, sensitivity of the screening tool increased above 90 percent \& specificity above 80 percent. The sensitivity \& specificity pattern of various sepsis screen parameters \& their combination has been shown in Table 2.

Table 2: The Sensitivity \& Specificity Of Sepsis Screen Parameters

\begin{tabular}{|c|c|c|c|}
\hline S. No. & Screening parameters & $\begin{array}{l}\text { Sensitivity } \\
(\%)\end{array}$ & $\begin{array}{l}\text { Specificity } \\
(\%)\end{array}$ \\
\hline 1. & $\begin{array}{l}\text { Raised micro ESR }\left(>15 \mathrm{~mm} \text { in } 1^{\text {st }} \mathrm{hr} \text { or Age }+3 \text { in } 1^{\text {st }}\right. \\
\mathrm{hr} \text { in }<3 \text { days old })\end{array}$ & 76.92 & 32.43 \\
\hline 2. & $\begin{array}{l}\text { TLC (Less than } 5000 / \mathrm{cmm} \text { or } 25000,30000 \& 21000 \\
\text { at birth, } 12-24 \mathrm{hrs} \& \text { day } 2 \text { onwards.) }\end{array}$ & 80.76 & 72.97 \\
\hline 3. & $\mathrm{ANC}(<1500 / \mathrm{cmm})$ & 84.61 & 79.72 \\
\hline 4. & I/T Ratio( $>0.2)$ & 84.61 & 86.49 \\
\hline 5. & I/M Ratio(>.3) & 80.76 & 79.72 \\
\hline 6. & Platelet count $(<1.5$ lakh $)$ & 73.07 & 66.21 \\
\hline 7. & $\begin{array}{l}\text { PBF (toxic granules, cytoplasmic vacuolations \& } \\
\text { Dohle bodies) }\end{array}$ & 76.92 & 75.67 \\
\hline 8. & $\begin{array}{l}\mathrm{CRP}\left(>16 \mathrm{mg} / \mathrm{lt} \text { on } 1^{\text {st }} \& 2^{\text {nd }} \text { day, }>10 \mathrm{mg} \text { on }\right. \\
\text { subsequent days) }\end{array}$ & 92.30 & 10.81 \\
\hline 9. & $>2$ parameters positive & 96.15 & 87.83 \\
\hline
\end{tabular}

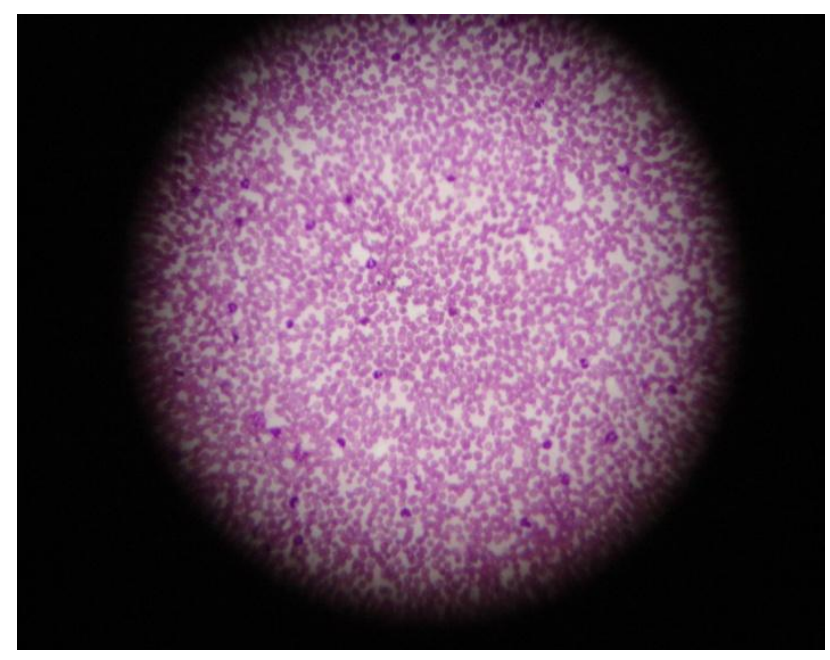

Figure 1: Showing leucocytosis in giemsa stain; $\mathrm{X} \times 400$

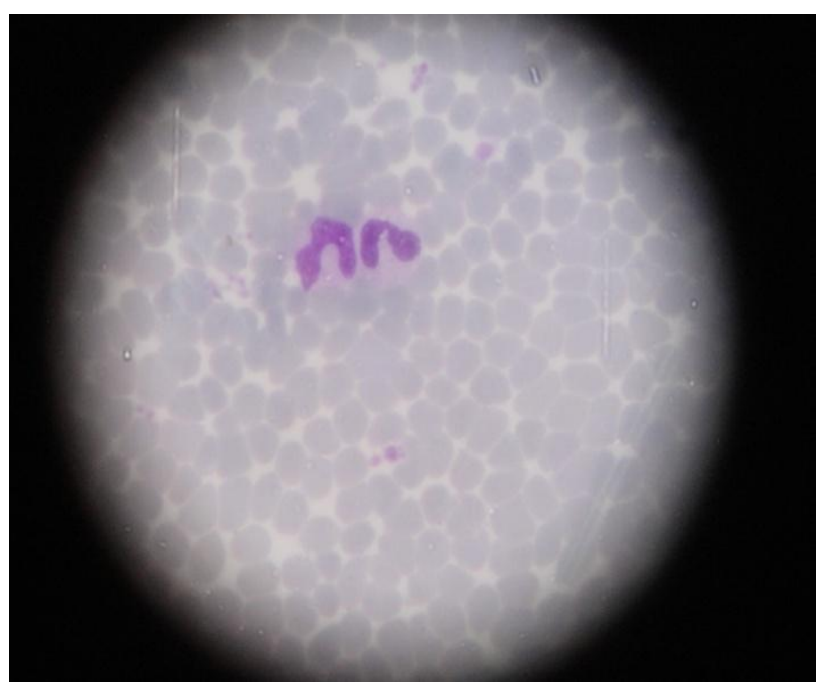

Figure 2: Showing band cells in giemsa stain; $\mathrm{X} x$ 1000 


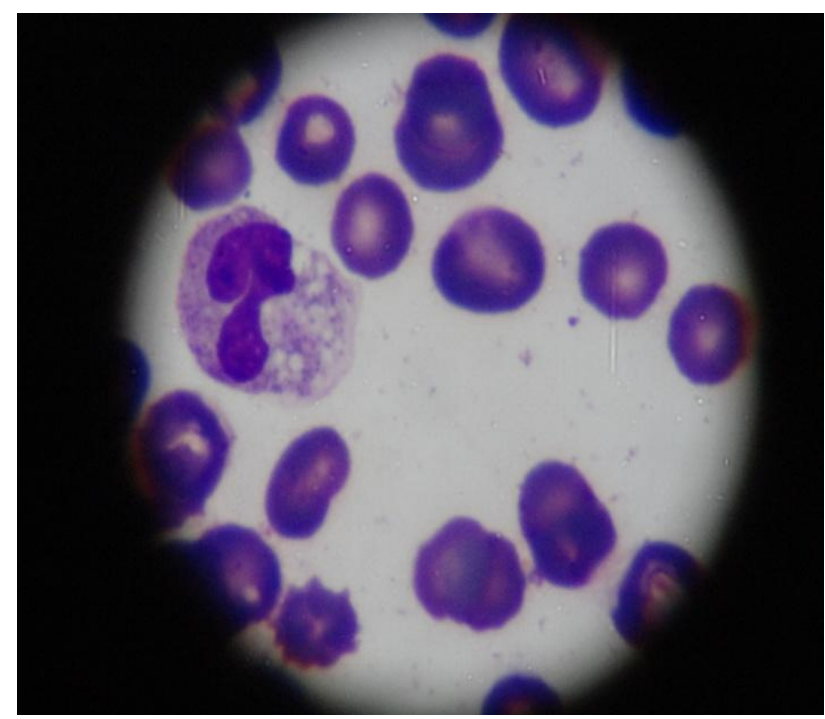

Figure 3: Showing immature polymorph with cytoplasmic vacuolations in giemsa stain; $\mathrm{X} \mathrm{X}$ 1000

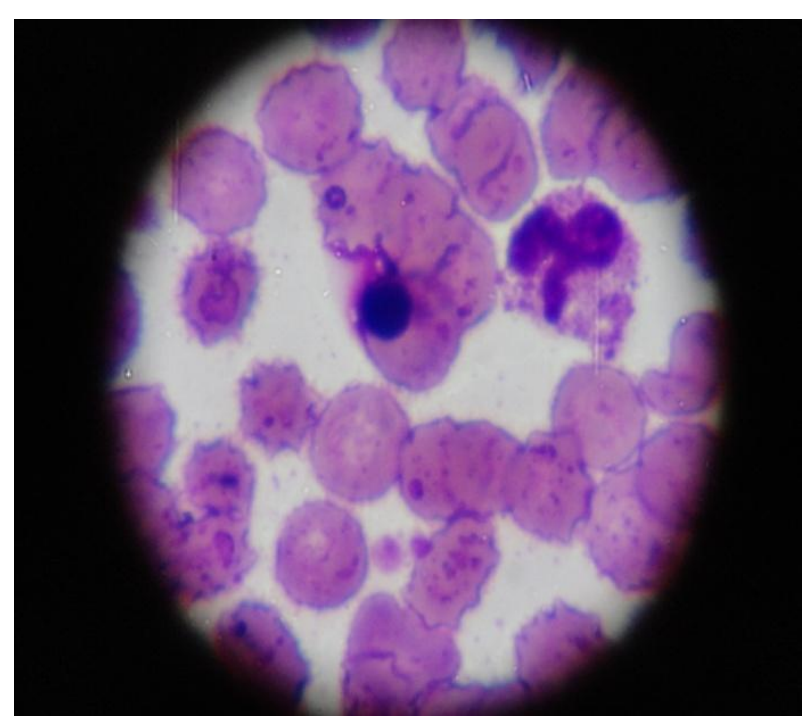

Figure 4: Showing immature polymorph with toxic granulations in giemsa stain; X x 1000

\section{DISCUSSION}

Neonatal septicemia is still a leading cause of mortality and morbidity in developing countries like India. The value of the sepsis screen is of prime significance in the diagnosis of neonatal septicaemia.

Further, newborns who develop sepsis often deteriorate rapidly. Because the failure or delay in treatment is likely to result in significant mortality and morbidity, early and efficient diagnosis is challenging to the clinician. The blood culture not only takes time, but is also complicated, with a low yield. Blood culture is still the "Gold standard" for the diagnosis of septicemia in neonates and should be done in all cases of suspected septicemia.

In the present study Maximum neonatal sepsis cases $(68 \%)$ were found of less than 3 days old age neonates (early onset septicemia) as compared to neonates aged more than 3 days (late onset septicemia) (32\%), Similar observations were seen in the study done by National Neonatal and Perinatal Database ${ }^{7} \&$ Sriram $^{8}$.

Out of 100 cases, 72 patients were male \& 38 were female with a high prevalence in the age group of 24-48 hours. Present study showed male preponderance with a ratio of $2.57: 1$. Khair et $\mathrm{al}^{5}$ \& Bhat \& $\mathrm{Rao}^{9}$ observed male, female ratio as 1.39:1 \& 1.08:1 respectively.

In the present study, the blood culture yield was $26 \%$. This was similar to the $28.6-42.2 \%$ yield which was obtained by many authors $(7,10)$. A much lower yield (14\%) has been reported by Varsha et $\mathrm{al}^{2}$. In the present study, the treatment of the mothers of at -a -risk neonates and the single blood culture samples could have contributed to the low culture yield.

Gram negative organisms formed the majority of the isolates as compared to Gram positive organisms $(65.38 \% \mathrm{Vs} 34.62 \%$, respectively) in the present study. This is comparable with studies conducted by $\mathrm{NNPD}^{7}$, Jaswal et $\mathrm{al}^{10} \&$ Sriram $^{8}$. The most common organism isolated in present study was E.coli while in other studies it was Klebsiella Pneumoniae.

The traditional sepsis work up included various haematological parameters and CRP. In the present study, the sensitivity of the haematological screening parameters and CRP varied from 73.03$92.30 \%$.

The total leukocyte count and the $\mathrm{B}: \mathrm{N}$ ratios have been correlated with an increased risk of bacterial infections in neonates. However, they had a wide range of sensitivity (17-90\%). ${ }^{9}$ In our study, the sensitivity was $80.76 \%$ for TLC and B: N ratio. Neutropenia was observed in $84.61 \%$ of the culture proven sepsis cases. Degenerative changes in 
neutrophils like cytoplasmic vacuolization and toxic granulation were reported to be a valuable adjunct in the early detection of neonatal bacterial infection. Sharma et $\mathrm{al}^{11}$ found a sensitivity of TG in $60 \%$ and $\mathrm{CV}$ of $15 \%$ among the proven sepsis cases. In contrast, we observed a sensitivity of $76.92 \%$ in TG/CV.

The micro-ESR is an inexpensive, easy bedside screening test. Its sensitivity ranges from $30 \%$ to $73 \%$ in proven sepsis cases. ${ }^{2,9}$ In the present study, sensitivity of micro-ESR was $76.42 \%$.

Thrombocytopenia as an important parameter in supporting the diagnosis of sepsis has been described, although it appears to be a late finding and to be nonspecific. ${ }^{9}$ The positivity of thrombocytopenia was $73.07 \%$ in our study.

Benitz et $\mathrm{al}^{12}$ found that the sensitivity of CRP in culture proven EOS rose from $35 \%$ at the initial evaluation to $78.9 \%$ in next 24 hours. They also opined that the sensitivity of a normal CRP at the initial evaluation is not sufficient to justify withholding antibiotic therapy and they suggested serial CRP estimations. The CRP level done on day 2 of life in our study, showed a sensitivity of only $16.9 \%$.

The importance of the serial measurement of the septic screens was demonstrated by Gerdes et $\mathrm{al}^{13}$, who performed two separate screens (WBC, I/T, CRP, micoESR), 12 to 24 hours apart. Infants who had normal initial screens were positive on repeat testing and identified all septic neonates. Our study has been limited by a one- time evaluation of the screening parameters.

As the sensitivity and the specificity of the individual tests may not justify their individual use in newborn infants, a significant improvement of diagnostic capability when used in various combinations, has been studied. ${ }^{9}$ An above $80 \%$ sensitivity by the combination of any 2 or more positive tests in culture positive EOS was also reported earlier from Indian studies. ${ }^{9}$ We observed a sensitivity of $96.15 \%$ by the combination of any two or more parameters.

An accurate and timely diagnosis of early onset neonatal sepsis remains challenging to the clinician and the laboratory. A test with a rapid turnaround time, with $100 \%$ sensitivity which allows accurate diagnosis and appropriate antimicrobial treatment, is desirable. A reasonable specificity is also required to allow the antibiotics to be safely withheld in non-infected infants. The sensitivity of individual tests or combinations varies widely.

\section{CONCLUSION}

We concluded by present study that the value of the sepsis screen is more for excluding the diagnosis of neonatal septicaemia which can be done reasonably if two screens 12-24 hours apart are negative. The Hematologic profile that we studied is a simple, quick and cost effective tool in the early diagnosis of neonatal sepsis. The sensitivities of the traditional haematological screening parameters and CRP are satisfactory in neonates with blood culture positive early onset infections. The sensitivity of a combination of any two or more parameters is more satisfactory, relatively better sensitivity is likely in symptomatic than in asymptomatic neonates. Because an early onset neonatal infection is a serious but treatable condition whose treatment should not be missed or delayed, a test or a combination of tests with a high sensitivity is desirable. Blood culture is still the "Gold standard" for the diagnosis of septicemia in neonates and should be done in all cases of suspected septicemia. Since symptoms suggestive of sepsis may be caused by a variety of other illnesses, confirmation of sepsis by the sepsis screen tests may help in avoiding unnecessary antibiotic therapy.

\section{REFERENCES}

1. Aggarwal R, Sarkar N, Deorari AK, Paul VK: Sepsis in the newborn. Indian $J$ Pediatr 2001; 68: 1143-1147.

2. Varsha, Rusia U, Sikka M, Faridi MM, Madan N: Validity of hematologic parameters in identification of early and 
late onset neonatal infection. Indian $\mathbf{J}$ Pathol Microbiol 2003; 46:565-8.

3. Mehr S and Doyle LW. Cytokines as markers of bacterial sepsis in newborn infants: a review. Pediatr Infect Dis J 2000; 19: 879-887.

4. Rodwell RL, Leslie AL, Tudehope Dl: Early diagnosis of neonatal sepsis using a Haematological scoring system. J Pediatr, 1988; 112:161-6.

5. Khair KB,Rahman MA,Sultana T,Roy C, Rahman MQ, Shahidullah M, Ahmed AN: Role of hematologic scoring system in early diagnosis of neonatal septicaemia. BSMMU J 2010; 3(2): 62-67.

6. Manroe BL, Weinberg AG, Rosenfeld CR, Browne R. The neonatal blood count in health and disease. I. Reference values for neutrophilic cells. J Pediatr 1979; 95:8998.

7. National Neonatal-Perinatal Database2000. National Neonatology Forum, India.

8. Sriram R. Correlation of Blood culture results with the Sepsis score and the Sepsis screen in the diagnosis of Neonatal Septicemia. Int J Biol Med Res. 2011; 2(1): 360-368.

9. Bhat $\mathrm{R} \&$ Rao $\mathrm{A}$ : The performance of haematological screening parameters and CRP in earlyonset neonatal infections. Journal of clinical \& diagnostic research 2010; 4(6): 3331-3336.

10. Jaswal RS, Kaushal RK, Goel A, Pathania $\mathrm{K}$. Role of Creactive protein in deciding duration of antibiotic therapy in neonatal septicemia. Indian Pediatr. 2003; 40:880883.

11. Sharma M, Goel N, Chaudhary U, Aggarwal R, Arora DR. Bacteraemia in Children. Indian J Pediatr. 2002 Dec; 69(12): 1029-32.
12. Benitz WE, Han MY, Madan A, Ramachandra P. Serial serum C-reactive protein levels in the diagnosis of neonatal infection. Pediatrics 1998; 102:e41.

13. Gerdes JS and Polin R. Early Diagnosis and Treatment of Neonatal Sepsis. Indian J Pediatr. 1998; 65(1): 63-78. 